\title{
Load capacity of anchors embedded into concrete and multi-layer façade slabs
}

\author{
J.K. Szlendak \\ State School of Higher Professional Education in Suwalki, Suwatki, Poland \\ D. Tomaszewicz \\ Faculty of Civil and Environmental Sciences, Bialystok University of Technology, Biatystok, Poland
}

\begin{abstract}
This paper presents the estimation of the load capacity of steel bonded anchors in concrete and multi-layer elements, in various arrangements and configurations, starting from single anchors perpendicular to the surface of the concrete element and ending with diagonal anchors bonded at 30,45 and 60 degrees. The estimates of load capacity used analytical models regarding, among others: individual anchors for pulling out taking into account the shear force of the texture layer and the anchor fixing factor (with or without lever arm); single concrete anchors for pulling out in full concrete elements and three-layer concrete elements as well as single diagonal anchors (without taking into account shear force). The first stage of experimental research included steel anchors bonded at an angle of 90 degrees in 22 three-layer samples and 10 samples with concreted anchors ( 7 solid samples and 3 three-layer samples) at different anchorage depths.at various anchoring depths. In the second stage, steel anchors concreted in concrete samples were tested. The third stage consisted of double-bolt anchor systems bonded at 30 and 45 degrees angles. The last, fourth stage was experimental study of three-bolt anchors. Experimental research was used to verify the theoretical load capacity of this type of connections in the external walls of large slab panel buildings. The results of experimental studies were compared with 56 numerical calculations made in ANSYS software and theoretical estimates according to the proposed analytical models.
\end{abstract}

\section{INTRODUCTION}

The theoretical estimation of the resistance of anchors has been the subject of many publications (Eligehausen et al. 2006, Ballarini et al. 1986). Usually, such estimates are preceded by experimental studies (Eligehausen et al. 2006, Eligehausen \& Appl J. 2006, Červenka et al. 1991), as well as numerical analysis using MES programs and environments (Eligehausen \& Appl J. 2006). In the work so far, only the anchors perpendicular to the surfaces of the concrete solid elements have been tested. This article also analyzes the anchors fixed at an angle (30, 45 and 60 degrees), extended with groups of anchors in two- and three-anchor systems, the load capacity of which was checked simultaneously.

\section{THEORETICAL ESTIMATION OF THE ANCHORS RESISTANCE- PROPOSED MODELS}

Load capacity of a single steel anchorglued in the concrete block has been developed by (Słowik \& Błazik-Borowa 2001) and their formula can be written as:

DOI: $10.1201 / 9781003132134-46$ 


$$
P=\pi \cdot d \int_{0}^{h e f} \tau_{p} \mathrm{dx} \rightarrow P=\pi \cdot d \cdot \tau_{p} \cdot h_{e f}[k N]
$$

where $d$-anchor diameter, [mm]; $\tau_{p}$ - adhesion stress, depending on the type of epoxy resin, $\left[\mathrm{N} / \mathrm{mm}^{2}\right] ; h_{e f}-$ lengths of effective anchors of individual anchors in samples, [mm].

In the experimental research, there were established the ultimate failureload of the joints anchored in the concrete blocks. Due to the nature of the impact of these loads in three-layer models, see Figure 1, the Authors extend formula (1) with the algebraic sum of the shear force of the top textured layer, the displacement of which is the resistance to the force pull-out the anchors. This model is described by the formula (2):

$$
P_{g r}=\pi \cdot d \int_{0}^{h e f} \tau_{p} d x=\pi \cdot d \cdot \tau_{p} \cdot h_{e f}+\frac{V}{\alpha_{M}}[k N]
$$

where $V$ - shear force of the top textured layer, [kN]; $\alpha_{M}$ - anchor fastening factor (shear loads with lever arm $\alpha_{M}=1.0$ or shear loads without lever arm $\alpha_{M}=2.0$ ) (ETAG 001 Annex C), [-].

When dealing with single anchors, the authors used the formula (1) and (2). However, in the case of anchors concreted in solid concrete elements, it was not necessary to take into account the effect of the shear force. For the group of anchors as it is shown in Figure 2. the theoretical resistance estimation is given using the formula (3):

$$
P_{g r}=\pi \cdot d \int_{0}^{h e f} f_{\text {ck.cube }} d x=\pi \cdot d \cdot f_{\text {ck.cube }} \cdot h_{e f}[k N]
$$

where $f_{\text {ck.cube }}$ - strength characteristic cube compressive, $\left[\mathrm{N} / \mathrm{mm}^{2}\right]$.

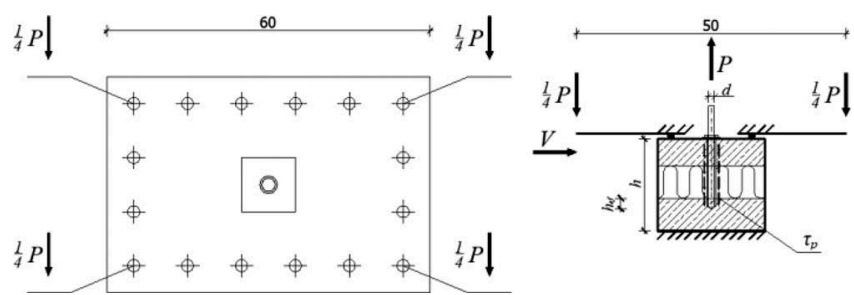

Figure 1. Scheme of three-layer sample load with anchor bonded perpendicularly.
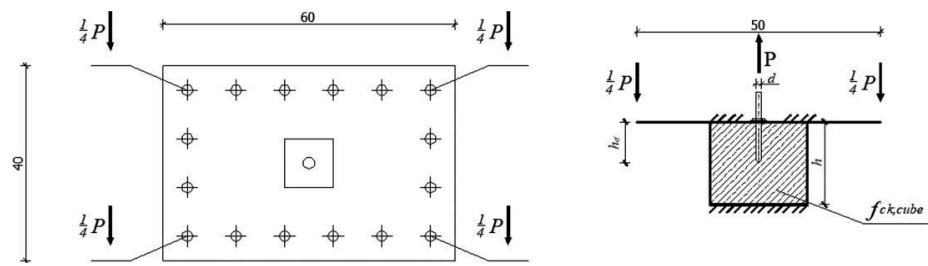

Figure 2. Scheme of single-layer sample load with anchor concreted perpendicularly. 
The value of the $\alpha_{M}$ coefficient, depending on the method of fastening and the nature of failure of the anchor, may be taken in accordance with the recommendations (ETAG 001).

Another theoretical model were discovered to describes the failure of diagonal bonded anchors at angles of $60^{\circ}, 45^{\circ}$ and $30^{\circ}$ (Figure 3). It does not take into account the effect of the shear force of the textured layer due to the lack of experimental verification. The failure load is estimated as:

$$
P_{g r}=\pi \cdot d \int_{0}^{h e f} f_{c k, c u b e} d x=\pi \cdot d \cdot f_{c k, c u b e} \cdot h_{e f}+\frac{V}{\alpha_{M}}[k N]
$$

where $\alpha$ - angle of inclination of diagonal anchors, $\left[^{\circ}\right]$.

Moreover, for two-anchor systems (Figure 4), the failure load was proposed equal to:

$$
P_{g r}=\frac{\pi \cdot d \int_{0}^{h_{e f 1} \cos \alpha_{1}}\left(\tau_{p} \cdot s\right) d s+\pi \cdot d \int_{0}^{h_{e f 2} \cos \alpha_{2}}\left(\tau_{p} \cdot s\right) d s}{2 c+2 l_{e f 1.2}}+\frac{V}{\alpha_{M}}[k N]
$$

where $h_{e f 1}, h_{e f 2}$ - effective anchor lengths of individual anchors, [mm]; s - distance between the anchors in the axes, [mm]; c - thickness of the epoxy resin covers between the anchor and the concrete substrate, $[\mathrm{mm}] ; l_{e f 1.2}-$ the length of total anchorage in the samples, $[\mathrm{mm}]$.

In the case of three-anchor systems, a theoretical resistance is equal to:
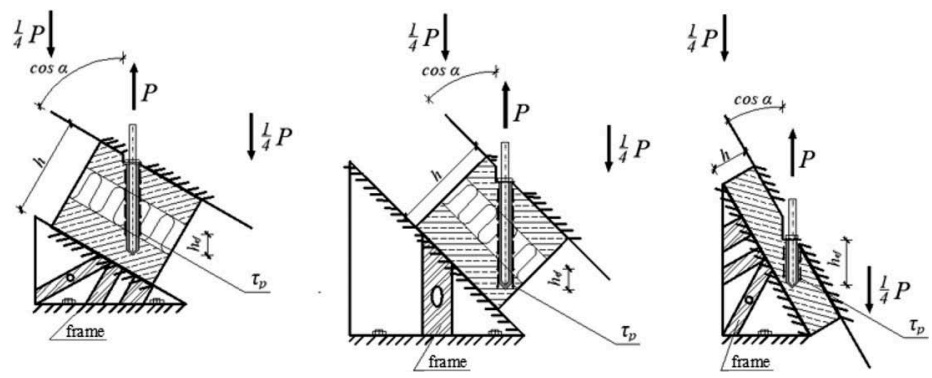

Figure 3. Sample load diagram with single diagonal anchors at $60^{\circ}, 45^{\circ}$ and $30^{\circ}$ respectively.

a)

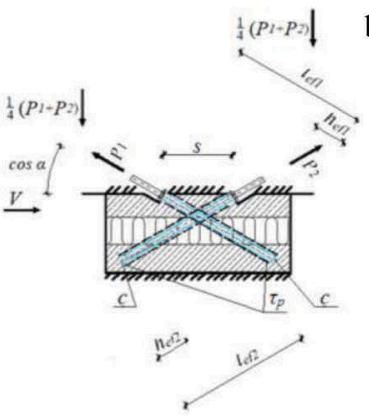

b)

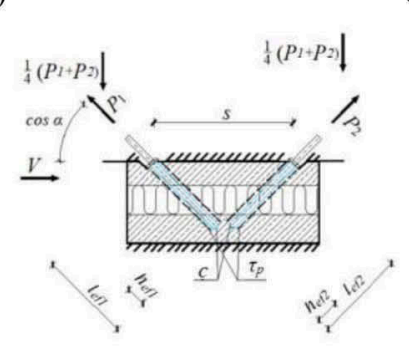

c)

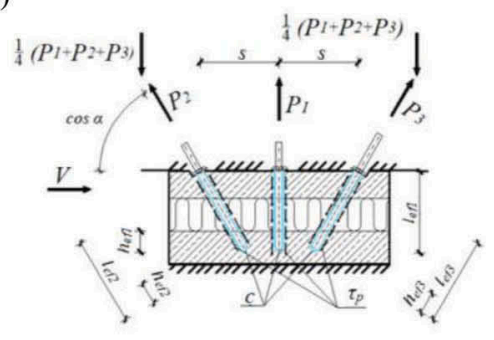

Figure 4. Diagram of a three-layer sample load in: a) a two-anchor system at an angle of $30^{\circ}$; b) a twoanchor system at an angle of $45^{\circ}$; c) a three-anchor system at an angle of $60^{\circ}$. 


$$
P_{g r}=\frac{\pi \cdot d \int_{0}^{h_{e f 1} \cos \alpha_{1}}\left(\tau_{p} \cdot s\right) d s+\pi \cdot d \int_{0}^{h_{e f 2}}\left(\tau_{p} \cdot s\right) d s+\pi \cdot d \int_{0}^{h_{e f 3} \cos \alpha_{3}}\left(\tau_{p} \cdot s\right) d s}{3 c+2 l_{e f 2,3}+l_{e f 1}}+\frac{V}{\alpha_{M}}[k N]
$$

and can be written as bellow:

$$
P_{g r}=\frac{\pi \cdot d \cdot \tau_{p} \cdot s \cdot h_{e f 2} \cdot \cos \alpha_{2}+\pi \cdot d \cdot \tau_{p} \cdot 2 s \cdot h_{e f 1}+\pi \cdot d \cdot \tau_{p} \cdot s \cdot h_{e f 3} \cdot \cos \alpha_{3}}{3 c+2 l_{e f 2,3}+l_{e f 1}}+\frac{V}{\alpha_{M}}[k N]
$$

where $h_{e f 2}=h_{e f 3}-$ effective lengths of diagonal anchorages, [mm]; $h_{e f 1}$ - effective length of the anchorage at an angle of 90 degrees, $[\mathrm{mm}] ; l_{e f 2.3}$ - the length of the total anchoring of diagonal anchors in the sample, [mm]; $l_{e f 1}$ - the length of the total anchoring of the anchor perpendicular to the sample surface, [mm].

Due to taking into account the parameters of the resin cover $c$ and the total anchorage length $\boldsymbol{l}_{\boldsymbol{e}}$, presented estimations achieve similar results with the numerical FEM simulation and experimental tests. A different approach to analytical calculations was proposed in (Szlendak et al., 2018).

\section{EXPERIMENTAL TESTS AND MES MODELS}

Experimental tests of steel anchor resistance were carried out in four stages. In the first stage, 32 specimens with 90-degree anchors were tested, in the second - 12 with single diagonal anchors, in the third -8 with two-anchor 30 and 45 degrees systems and in the fourth stage - 4in three-anchor systems with the two 60-degree anchors and one-90 degree. The increase the pull-out force in the anchors in the experimental tests and FEM analysis was $0,5 \mathrm{kN} / \mathrm{s}$. In addition (apart from individual diagonal anchors), a shear force was applied to the top texture layer equal to $1,4 \mathrm{kN}$. Tests of natural scale specimens were carried out at the Bialystok University of Technology, Department of Building Structures.

In the 90 degree bonded anchorages test, 22 tests of the interaction load capacity of bonded anchors were carried out, i.e. to obtain a relation of the bonding force of the bonded anchor and the shear force (Figure 5) of the upper concrete layer (textured layer).

The next stage of the tests is to check the resistance to stress of diagonal anchorages.

The tests of bonded diagonal anchorages at angles of 60 degrees, 45 degrees and 30 degrees were carried out in 4 tests for each anchorage angle. Figure 6 shows one of the failure models of the bonded anchorage at 60 degrees.
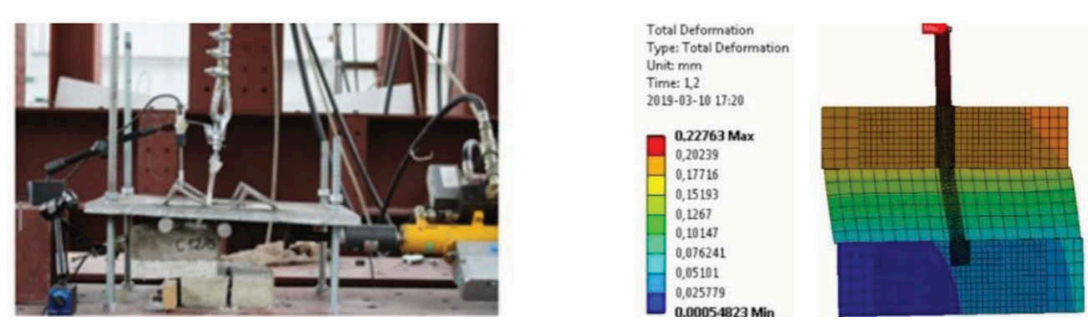

Figure 5. Failure models of 90 degree bonded anchorage: experimental test and FEM model. 

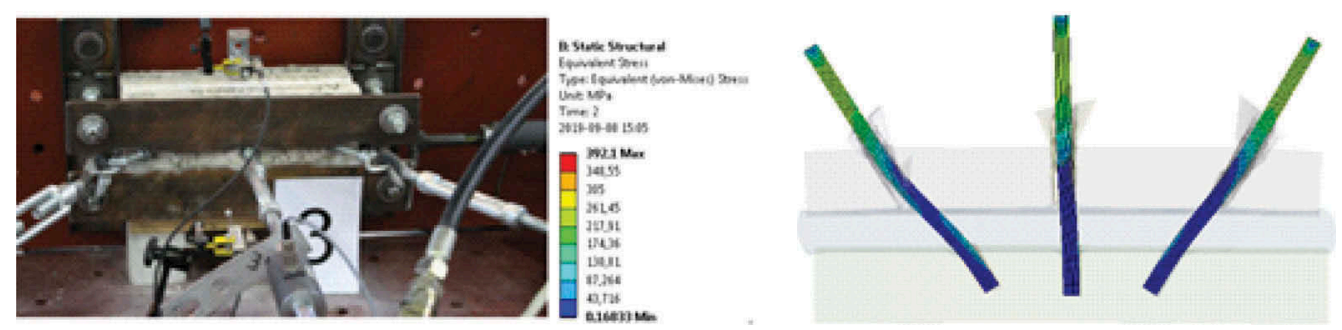

Figure 6. Failure models of three-anchor anchorages bonded at an angle of 60 degrees: experimental test and FEM model.

The model for anchoring made at an angle of 30 degrees was designed as a single-layer with a construction layer thickness of $6 \mathrm{~cm}$ due to the large inclination angle.

- Anchorages concreted at an angle of 90 degrees

In the solid concrete samples, depth of anchorages were used of $8.5 \mathrm{~cm} ; 11.5 \mathrm{~cm} ; 14.5 \mathrm{~cm}$; $15 \mathrm{~cm} ; 15.5 \mathrm{~cm} ; 16 \mathrm{~cm}$ and finally through the full cross-section, i.e. $17 \mathrm{~cm}$.

As for the three-layer models, the anchors were concreted at the depths of $2 \mathrm{~cm}, 4 \mathrm{~cm}$ and $6 \mathrm{~cm}$ of the cross-section of the construction layer.

- Two-anchor anchorages bonded under angle at 30 and 45 degrees

This stage of the tests consists of complex two-anchor systems at an angle of 30 degrees and 45 degrees.

- Three-anchor anchorages have been bonded under angle at 60 degrees. This is the last stage of the test in which the three-anchor systems consisted of two anchors at an angle of 60 degrees and anchors at an angle of 90 degrees between them (Figure 6).

\section{COMPARISON OF THEORETICAL ESTIMATIONS AND FEM MODELS WITH EXPERIMENTAL RESULTS}

\subsection{Comparison of the results for bonded anchors at an angle of 90, 60, 45 and 30 degrees}

Table 1 summarize the results for the anchor bonded. The results correspond to the most unfavourable anchorage $\left(h_{e f}=2 \mathrm{~cm}\right)$.

Table 1. Comparison of the results - steel anchors bonded at an angle of 90 degrees.

\begin{tabular}{|c|c|c|c|c|}
\hline \multirow[b]{3}{*}{ Description } & \multicolumn{2}{|c|}{ Theoretical estimate } & \multicolumn{2}{|c|}{ FEM calculations - ANSYS } \\
\hline & Force & displacement & Force & displacement \\
\hline & $\mathrm{kN}$ & $\mathrm{mm}$ & $\mathrm{kN}$ & $\mathrm{mm}$ \\
\hline The result of the experiment & 8.40 & 0.10 & 8.40 & 0.10 \\
\hline Calculation result & 8.43 & 0.14 & 10.00 & 0.14 \\
\hline Difference & 0.03 & 0.04 & 1.60 & 0.04 \\
\hline
\end{tabular}




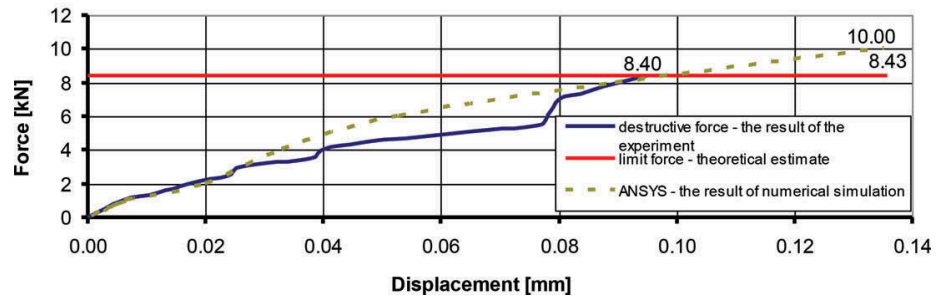

Figure 7. Comparison of theoretical estimation, experimental tests and numerical simulation for an anchor bonded at 90 degrees to the surface of the block model.

\subsection{Comparison of the results for anchors concreted at an angle of 90 degrees}

The anchorages in solid concrete and three-layer samples at a depth of only $2 \mathrm{~cm}$ were compared (Table 2).

\subsection{Comparison of the results of bonded two-anchors at an angle of 30 and 45 degrees}

In the case of the most unfavourable of the anchorages at an angle of 30 degrees, the difference between the experimental result and the FEM model was $1.20 \mathrm{kN}$ but in case of the theoretical estimatethis difference was $9.99 \mathrm{kN}$.

\subsection{Comparison of the results of bonded three-anchors at an angle of 60 degrees}

The three-anchors were two steel anchors bonded in at an angle of 60 degrees and one the anchors bonded in at an angle of 90 degrees. The results of a single model are presented in Table 3. The forces in individual anchors obtained in experiment are added, see Figure 8.

Table 2. Comparison of the results of models with steel anchors concreted at an angle of 90 degrees.

\begin{tabular}{|c|c|c|c|c|}
\hline \multirow[b]{3}{*}{ Description } & \multicolumn{2}{|c|}{ Theoretical estimate } & \multicolumn{2}{|c|}{ FEM calculations - ANSYS } \\
\hline & Force & displacement & Force & displacement \\
\hline & $\mathrm{kN}$ & $\mathrm{mm}$ & $\mathrm{kN}$ & $\mathrm{mm}$ \\
\hline The result of the experiment & 15.00 & 0.17 & 15.00 & 0.17 \\
\hline Calculation result & 12.70 & 0.12 & 16.00 & 0.09 \\
\hline Difference & 2.30 & 0.05 & 1.00 & 0.08 \\
\hline
\end{tabular}

Table 3. Comparison of the results of models with steel anchors bonded at an angle of 60 degrees.

\begin{tabular}{llllll}
\hline & \multicolumn{2}{l}{ Theoretical estimate } & & \multicolumn{2}{l}{ FEM calculations - ANSYS } \\
\cline { 2 - 3 } & Force & displacement & & Force & displacement \\
\cline { 2 - 3 } \cline { 5 - 6 } Description & $\mathrm{kN}$ & $\mathrm{mm}$ & & $\mathrm{kN}$ & $\mathrm{mm}$ \\
\hline 0.17 & 26.30 & 0.30 & & 26.30 & 0.30 \\
0.12 & 30.48 & 0.42 & & 25.00 & 0.42 \\
0.05 & 4.18 & 0.12 & & 1.30 & 0.12 \\
\hline
\end{tabular}




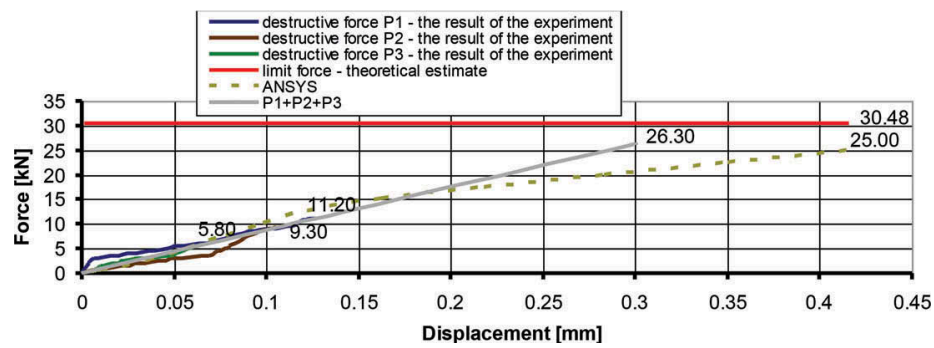

Figure 8. Comparison of theoretical estimate results, experimental tests and numerical simulation of athree-anchor bonded at 60 degrees to the surface of the block model.

A direct comparison of all group of anchors i.e. 90 degree bonded and also two and three anchors diagonal anchorages have been described in (Szlendak et al. 2018a and 2018b).

\section{CONCLUSIONS}

The experimental tests of anchors were carried out on two types of elements, made of C12/15 and C30/37 concrete with the use of epoxy resins: R-KER Bonded Anchors and Sika AnchorFix-1. At all stages of the tests, efforts were made to obtain the failure force which damage the anchorage. Theoretical estimations of these failure loads are given.

Most of the results showed high convergence. Larger discrepancies in the results occurred in the models with concrete anchors. This may be because the calculation models do not take into account the phenomenon of sample destruction caused to concrete fracture mechanics. This issue will be investigated in the future.

\section{REFERENCES}

Eligehausen R., Cook R. A., Appl J. 2006.Behaviour and design of adhesive bonded anchors. ACI Structural Journal, pp. 822-831.

Ballarini R., Shah S. P., Keer L. M. 1986. Failure characteristics of short anchor bolts embedded in a brittle material.The Royal Society London A 404, pp. 35-54.

Červenka V., Pukl R., Eligehausen R. 1991. Fracture analysis of concrete plane-stress pull-out tests. Institut für Werkstoffe im Bauwesen.

Eligehausen R., Appl J. 2006. Behavior and design of fastenings with bonded anchors: numerical analysis and experimental verification. Institute for Construction Materials, Univ. of Stuttgart, Germany.

Słowik M., Błazik-Borowa E. 2001. The influence of the choice of reinforcement's bars on stress distribuction in concrete element. EksploatacjaiNiezawodność $n r$ 5/2001, Polskie Naukowo-Techniczne Towarzystwo Eksploatacyjne, pp. 43-46 (in Polish).

ETAG 001. 2013. Guideline For European Technical Approval of Metal anchors for use in concrete. Part one: Anchors in general.

Szlendak J. K., Jablonska-Krysiewicz A., Tomaszewicz D. 2018a.Analytical modelling of a three layer wall system of strengthening for large-panel slab buildings by means of bonded anchors, MATEC Web Conf., Volume 174, pp. 859-868, ECCE 2018, Opole, Poland.

Szlendak J. K., Jablonska-Krysiewicz A. \& Tomaszewicz D. 2018b. Comparative Analysis of Oblique Bonded Anchors with Point Anchors Fixed in the Concrete Structural Layer of Buildings of Large Slab. $3^{\text {rd }}$ World Multidisciplinary Civil Engineering - Architecture - Urban Planning Symposium; WMCAUS 18-22 June 2018, At Prague, Czech Republic. 